\title{
Pensamento computacional para alunos do ensino básico do sertão baiano
}

\author{
Beatriz S. de Santana ${ }^{1}$, José Amancio M. Santos ${ }^{1}$ \\ ${ }^{1}$ Programa de Pós-Graduação em Ciência da Computação \\ Universidade Estadual de Feira de Santana (UEFS) \\ Feira de Santana - BA, Brasil \\ beatrizsecomp@gmail.com, zeamancio@uefs.br
}

\begin{abstract}
Several countries have sought to include computing in their school curricula, as they identify it as a helpful way to achieve the development of society. In Brazil, computer education still occurs disconnected from the curriculum and some regions are less favored by such actions. In this work, we present a creative computing course aimed at elementary school students from a city in the inland of Bahia. We verified the development of creativity, collaboration and others that are little stimulated in traditional teaching environments.
\end{abstract}

Resumo. Diversos países têm buscado inserir a computação em seus currículos escolares, pois identificam que é uma forma útil para alcançar o desenvolvimento da sociedade. No Brasil, o ensino computacional ainda ocorre de forma desconectada do currículo e algumas regiões são menos favorecidas por tais ações. Apresentamos neste trabalho um curso de computação criativa voltado para alunos do ensino fundamental de uma cidade do interior da Bahia. Verificamos o desenvolvimento de habilidades como criatividade, colaboração entre outras que são pouco estimuladas em ambientes de ensino tradicional.

\section{Introdução}

Na contemporaneidade, a tecnologia está presente nos mais diversos lares em diferentes proporções e age como fonte de informação, encurtadora de distâncias, facilitadora de tarefas, entre outras funções. Diante deste contexto, países como EUA, Israel, Reino Unido, Nova Zelândia e Austrália, buscam inserir conhecimentos tecnológico em seus currículos escolares visando uma alto padrão de educação. Os desenvolvedores de políticas educacionais destes países identificaram que o ensino computacional é fundamental para garantir competitividade econômica [Gal-Ezer and Stephenson 2014, Bocconi et al. 2016]. Pesquisadores também identificaram que o ensino de aspectos computacionais é um grande impulsionador do desenvolvimento de habilidades como criatividade, pensamento lógico, colaboração, entre outras. Tais aspectos são benéficos para todas as áreas de conhecimento e seu melhor desenvolvimento deve ser proporcionado por meio do ambiente escolar [Voogt et al. 2013, CSTA and ACM 2016].

No Brasil, as iniciativas para inclusão da computação na educação ocorrem de forma desconectada do currículo escolar [Santos et al. 2018]. Apesar do reconhecimento da necessidade da inclusão do pensamento computacional na educação básica, há um consenso de que ainda existe a necessidade de compreensão de como trabalhar essas habilidades [SBC 2018]. Como forma de contornar a falta de iniciativas governamentais 
para o ensino de computação e compreender seus benefícios, pesquisadores têm realizados trabalhos pontuais [Lima et al. 2019]. Porém, tais iniciativas geralmente contemplam cidades próximas a instituições de ensino superior e, assim, as cidades mais afastadas e menos favorecidas ainda carecem de iniciativas deste tipo.

Nesse artigo, relatamos uma iniciativa efetuada em uma cidade do sertão baiano com estudantes do ensino fundamental. Essa experiência demonstra a viabilidade de incorporar o pensamento computacional para um público proveniente de cidades com baixo índices de desenvolvimento. Nesta ação, utilizamos um curso de computação criativa 1 elaborado na universidade de Harvard utilizando o software/ambiente Scratch.

\section{Fundamentação Teórica}

A computação está cada vez mais presente nas sociedades e seu ensino vem sendo identificado por diversos pesquisadores como um meio de desenvolver, além de habilidades computacionais, habilidades fundamentais para a vida século XXI [Cutumisu et al. 2019. Mohaghegh and McCauley 2016]. De acordo com [CSTA and ACM 2016], o ensino de ciência da computação é um meio de desenvolver habilidades necessárias para os estudantes do ensino básico. Voogt et al. (2013), apontam que os métodos de ensino atuais não são suficientes para a preparação do indivíduo que influenciará no futuro da comunidade em que ele convive. Por sua vez, Wing (2006) entende que estudantes do ensino básico necessitam desenvolver habilidades diretamente relacionadas à computação, pois tais habilidades já fazem parte dos processos naturais e se relaciona com processo aprendidos ao longo dos anos escolares, como, por exemplo, ler e realizar operações matemáticas. A autora popularizou o termo pensamento computacional, que diz respeito ao ensino de aspectos computacionais sem necessariamente fazer o uso do computador.

Países como Inglaterra, Austrália e Nova Zelândia, entre outros, já inseriram matérias próprias para o ensino de aspectos computacionais em seus currículos escolares [Heintz et al. 2016, Bocconi et al. 2016]. No Brasil, ainda não existem disciplinas de computação incorporadas à grade curricular. A inserção de 11 competência e habilidades computacionais na Base Nacional Comum Curricular (BNCC) 2 demonstra que os responsáveis pelas políticas educacionais já percebem a necessidade do ensino de tais aspectos. Porém, a inserção dessas habilidades e competências dentro da matéria da matemática e a falta de clareza sobre os conceitos exibidos demonstram que ainda existe a necessidade de melhor compreensão desses aspectos [SBC 2018]. Um ponto de destaque é a necessidade de difundir estes conceitos em municípios de pequeno porte [Torres et al. 2018].

\section{Computação Criativa em Piritiba}

Esta pesquisa vem sendo realizada no sertão baiano, em Piritiba, cidade localizada a 320 $\mathrm{km}$ de Salvador, capital da Bahia. A cidade possui cerca de 25 mil habitantes, número que se mantém nas últimas décadas devido a falta de oportunidades de trabalho na cidade [Santos et al. 2019]. Piritiba possui um baixo índice de desenvolvimento humano $(0,578)$, além de baixos índices de desenvolvimento da educação básica [IBGE 2020].

O curso de computação criativa foi realizado em um laboratório do polo do Instituto Federal Tecnológico da Bahia, na cidade. Tal escolha foi feita devido à falta de

\footnotetext{
${ }^{1}$ https://scratched.gse.harvard.edu

${ }^{2} \mathrm{BNCC}$ - documento normativo com referências obrigatórias para a estrutura curricular do ensino básico
} 
estrutura para realização do curso nas escolas públicas da cidade. O laboratório utilizado possui 15 notebooks e acesso à internet. O projeto está sendo realizado em parceria com a prefeitura, o que possibilitou o acesso às escolas e a disponibilização de um professor/facilitador. Além disso, o projeto é idealizado pelo Instituto Tecnológico de Piritiba (ITPi) ${ }^{3}$, que atua como agente articulador e responsável pelos aspectos organizacionais do curso. Pesquisadores da Universidade Estadual de Feira de Santana participam através da tradução do material, treinamento do professor e acompanhamento do projeto.

O estudo foi conduzido em 2018, com 45 alunos matriculados cursando o $8^{\circ}$ e $9^{\circ}$ ano do ensino fundamental; e em 2019, com 73 alunos matriculados que cursavam o 6ㅇ e $7^{\circ}$ anos do ensino fundamental. Participaram do projeto 72 alunos de escola pública e 46 alunos de escolas particulares. A carga horária foi de 30 horas. Parte do material não foi utilizado devido a falta de recursos físicos para realização práticas com hardware.

\section{Resultados}

Nesta seção, exibiremos as atividades de cada unidade, bem como os achados da sala de aula obtidos por meio de observação direta do professor ministrante e das reflexões dos alunos efetuadas no livro do estudante.

\subsection{Unidade 0}

O objetivo desta unidade foi a apresentação do Scratch e da metodologia de ensino. Inicialmente, os alunos foram convidados a refletir e realizar anotações sobre o modo como interagem com o computador e sobre quantas dessas interações dizem respeito à criatividade. As respostas giravam em torno do uso para visualização de vídeos e utilização de jogos. Nesse momento, foi observada a dificuldade de leitura e escrita dos alunos, principalmente daqueles advindos de rede pública de ensino.

Em seguida, os participantes realizam o cadastro no site do Scratch para criar, manter e compartilhar os seus projetos, além de explorar projetos de outros criadores. Nesse momento, os alunos demonstraram dificuldade ao manusear os notebooks, pois não estavam habituados com o uso do touchpad. Apesar disso, após o contato inicial, eles conseguiram realizar a exploração do site.

Ainda nessa unidade, os estudantes exploraram o ambiente do Scratch demonstrando grande interesse no uso da ferramenta e realizaram a criação de um projeto simples utilizando a movimentação de um personagem na tela. Isso gerou um alto grau de entusiasmo e reflexão sobre ideias de projeto futuros, como historias animadas e jogos. Ao final da unidade, eles demonstraram muito interesse em utilizar a ferramenta para realização de projetos. Porém, apresentaram queixas sobre a necessidade de escrever em diários a respeito de suas percepções. Um aspecto notado que os estudantes demonstraram prazer em compartilhar seus feitos, mesmo que iniciais, com os outros colegas e também demonstraram interesse em visualizar os projetos efetuados pelos colegas.

\subsection{Unidade 1}

Nesta unidade, os estudantes aprenderam aspectos relacionados a sequência e repetição. Para tanto, inicialmente, foi feita uma atividade desplugada, sem uso do computador,

\footnotetext{
${ }^{3}$ www.itpi.org.br
} 
que consistiu na tarefa de expressar uma sequência de movimentos de dança utilizando instruções verbais. Observamos alto grau de engajamento entre os alunos para que a atividade fosse efetuada corretamente. Ao identificar que as instruções descritas não eram suficientes para que os executores da dança conseguissem realiza-la da maneira idealizada, os estudantes conseguiram identificar também os motivos pelos quais, na atividade anterior, o personagem utilizado não efetuava a ação idealizada. Ao final da atividade, eles relataram que suas maiores dificuldades foram fazer com que, por meio das instruções dadas, os colegas realizassem os movimentos desejados e a criação de uma sequência lógica de passos que resultasse na execução da dança.

Em um segundo momento, os estudantes criaram sem muita dificuldade o projeto "gato dançante"com base em um tutorial disponível no site para que assim eles pudessem ter contato com novos comandos.

$\mathrm{Na}$ atividade seguinte, eles criaram um projeto utilizando apenas 10 blocos de instruções. Nesse momento, os estudantes apresentaram dificuldades para criar sequências lógicas e para utilizar estruturas de repetição, mesmo após utilizá-las no tutorial anterior. Apesar dessa limitação, os estudantes utilizaram sua criatividade para realizar projetos diversos com combinações diferentes dos mesmos blocos. Nesse momento, observamos que nas turmas mistas (alunos de escola pública e particular) os alunos apresentavam mais concentração e conseguiam auxiliar um ao outro durante o processo de criação do projeto. Nas turmas formadas exclusivamente por alunos de escola pública foi necessária a intervenção do professor por meio da apresentação de um projeto similar ao solicitado, para que assim os alunos entendessem como montar sua própria sequência lógica do projeto.

Nas outras atividades, os estudantes exploraram os projetos com o intuito de criar uma lista de favoritos. Observamos que os projetos escolhidos não eram relacionados ao nível de dificuldade e novidade e sim aos gostos pessoais dos alunos. Em seguida, eles aprenderam a depurar os projetos, demonstrando como identificaram os problemas encontrado e como corrigiram, além de debater com os colegas como eles realizaram a tarefa.

Por fim, os estudantes utilizaram os conhecimentos adquiridos na unidade para realizar uma colagem interativa sobre si mesmo. Ao início da atividade, eles apresentaram queixas sobre a necessidade de ser uma colagem em relação a suas próprias características e não as de outras pessoas, pois, de maneira geral, não consideravam suas vidas interessantes. Tal fato foi evidenciado por meio de falas como "minha vida não é interessante", "não faço muitas coisas legais durante o dia". Ao finalizar as atividades, eles deveriam compartilhar com os colegas, diferente das realizações anteriores. Nesse momento os estudantes não se sentiam motivados a compartilharem seus projetos. Muitos questionaram a necessidade de mostrar sua atividade. De maneira geral, os estudantes exibiram que gostariam de fazer essa atividade com base em outros personagens e tiveram ideias de como deixar a atividade mais interessante.

\subsection{Unidade 2}

Nessa unidade, foram apresentados aos conceitos de loops, eventos e paralelismo por meio da criação de projetos animados utilizando sons.

Na primeira atividade, os estudantes criaram o seu próprio grupo musical tendo 
um projeto desse tipo como base. Para tanto, eles utilizam diferentes atores, sons e formas de tornar o projeto interativo. Ao longo do processo, os participantes demonstraram prazer ao modificar o projeto base e torná-lo sua própria criação. Ao final da atividade, os alunos apontaram que a adição do som ao projeto deixou a criação de projetos mais interessante.

$\mathrm{Na}$ segunda atividade, foi solicitado que os estudantes criassem um projeto utilizando um quadrado alaranjado e um círculo roxo. Eles deveriam adicionar movimento estático aos desenhos criados, entendendo assim como realizar movimentações no Scratch. Para tornar a atividade mais interessante o professor premiou, em todas as turmas, os projetos mais criativos. Com isso observamos que a execução da tarefa foi feita com mais empenho e dedicação. Um fato muito observado foi o uso da criatividade de uma maneira mais ampla. Isto foi evidenciado por meio dos diferentes tipos de projetos exibidos e da utilização de blocos que ainda não tinham sido trabalhados anteriormente.

$\mathrm{Na}$ terceira atividade, os estudantes deram vida a um personagem realizando diferentes animações que são próximas as execuções efetuadas dos movimentos observados do mundo real. Os estudantes aprenderam a trocar trajes do personagem escolhido, utilizaram repetições e realizaram a movimentação dos atores. Alguns estudantes já tinham explorado trajes na atividade anterior por iniciativa própria. Eles tiveram mais facilidade na realização da atividade. Ao final, eles apresentaram momentos nos quais identificavam a repetição em seus dias a dias, foram pontuadas atividades como andar, comer, um dos estudantes deu o exemplo de quando a sua mãe o instrui a comer até que o prato esteja vazio.

Na quarta atividade, os estudantes realizaram a depuração de códigos para encontrar erros em projetos que utilizam os conceitos aprendidos nesta unidade. Devido ao maior grau de complexidade dos projetos, os estudantes tiveram mais dificuldades que na atividade da primeira unidade, porém todos conseguiram sanar as dificuldades e geralmente, esse processo foi efetuado sem ajuda de terceiros. A maior dificuldade observada foi depurar erros relacionados ao uso da caneta.

A quinta atividade consistiu na criação de um projeto próprio utilizando os conceitos aprendidos ao longo da unidade. Os estudantes criaram uma noite musical com base em um projeto apresentado e fizeram modificações no tema acrescentando diversos componentes tornando assim seus projetos bem diversificados.

\subsection{Unidade 3}

Na unidade 3 os alunos deveriam exercitar a colaboração e a criatividade. Para tanto, foi estimulado que eles reutilizem códigos e criem suas próprias narrativas colaborativas.

Inicialmente, os participantes criaram blocos de comando para realizar a ação de pular. A novidade com relação ao uso de blocos nas etapas anteriores foi a criação de seus próprios blocos. Os estudantes necessitaram utilizar conceitos de plano cartesiano para realizar a movimentação requerida pelo ato de pular. Por conta da grande dificuldade observada em todas as turmas para entender os aspectos relacionados ao plano cartesiano, para a conclusão foi necessária uma atividade desplugada para melhor compreensão do conceito.

Em seguida, os estudantes criaram conversas entre os atores do projeto. Eles utilizaram os conceitos computacionais de temporização e de transmissão para que as 
conversas entre atores fossem o mais próximo de um cenário real. Como os estudantes demonstraram dificuldades em realizar as tarefas de maneira sincronizada, foi feita uma atividade desplugada na qual eles deveriam obedecer a ordem de fala determinada para cada um. Assim, foi possível o entendimento da sequência correta que deveria ser seguida no diálogo e os alunos conseguiram concluir a tarefa.

A terceira atividade apresentou o conceito de mudança de palcos no Scratch. Nesse momento, os estudantes refletiram sobre as diferenças entre palco e personagem na plataforma sem grandes dificuldades, além de demonstrarem a fixação dos conhecimentos adquirido nas aulas anteriores. Nessa aula, observamos dificuldades com questões de proporções, ao mudar o cenário os participantes não conseguiam identificar a necessidade de mudança no tamanho do personagem para melhor adequação à nova cena.

Foram feitas atividades de depuração de códigos que utilizam os conceitos aprendidos e, assim, os estudantes puderam solucionar erros encontrados durante o processo de codificação. As atividades de depuração de códigos desta unidade foram realizadas sem grandes dificuldades.

A quinta atividade consistiu na criação de um desenho colaborativo para apresentar o conceito de remixagem. Nessa atividade, os estudantes criaram o desenho de uma criatura em três etapas: na primeira etapa foi desenhada a cabeça, na segunda, foi desenhado o meio da criatura (uma parte do corpo), e, por último, a parte inferior. Cada etapa foi efetuada por um aluno diferente. Assim, eles puderam ver como é feita a execução de processos em etapas por diferentes pessoas. Os estudantes consideraram a atividade divertida e exibiram diversas criaturas abstratas criadas no processo.

Por fim, os estudantes realizaram projetos com narrações de histórias de forma colaborativa. Eles iniciaram criando uma história e, após isso, compartilharam o seu feito para que outros colegas pudessem dar prosseguimento ao que foi criado. Nessa atividade, apesar dos alunos gostarem de criar as suas histórias e compartilha-las com os colegas, muitos deles não se sentiam a vontade para realizar modificações nos projetos criados por outros colegas.

\subsection{Unidade 4}

$\mathrm{Na}$ quarta unidade, foram introduzidos os conceitos computacionais de variáveis e listas por meio do desenvolvimento de jogos.

Os estudantes iniciaram esta unidade com reflexões em relação aos seus jogos preferidos, observamos, nesse momento, que tanto meninos quanto meninas compartilhavam o interesse por jogos semelhantes que variavam entre jogos de aventura e ação. Poucas meninas da turma externaram preferir jogos voltados ao vestuário feminino.

Em seguida, eles criaram alguns jogos interativos para aprenderem conceitos que seriam utilizados no projeto final da unidade. O primeiro jogo foi o labirinto, no qual, para vence-lo, um ator deveria se mover para chegar ao ponto final sem tocar nas paredes. Esse jogo foi realizado com base em um tutorial e foi desenvolvido sem grandes dificuldades. O segundo jogo foi o pingue-pongue, no qual o objetivo é não deixar a bolinha cair no chão. Nesse jogo, os alunos precisaram trabalhar com novos conceitos, os de variáveis e operadores, e observamos que as maiores dificuldades foram na compreensão do conceito de variáveis e de operadores relacionais. 
A próxima atividade foi a criação de um jogo que consistia no controle de um helicóptero utilizando os conceitos anteriores, garantindo que a pontuação só fosse obtida se o helicóptero não tocasse em objetos inseridos e não caísse. Os estudantes demonstraram dificuldades em propor formas para contabilizar a pontuação do jogo, já que esta se diferia das propostas nos jogos anteriores. Assim, o professor teve que apresentar possibilidades para que os estudantes colocassem em prática.

Após a aprendizagem de como utilizar pontuação, mudança de níveis, temporização, entre outras funções aprendidas com os jogos desenvolvidos anteriormente, os estudantes realizaram colaborativamente em dupla ou trios o incremento destas funções em um jogo previamente disponibilizado. Neste momento, identificamos que a maioria dos projetos era feita de forma independente. A maioria dos estudantes criava diferentes cópias do projeto para implementar cada função solicitada.

\subsection{Unidade 5}

Os estudantes iniciaram essa unidade relatando sobre a experiência vivida com a computação criativa até este ponto do curso, demonstrando domínio de conceitos anteriormente desconhecidos, como sequência, utilização de variáveis, conceitos envolvidos na criação de jogos e manifestaram o interesse em continuar utilizando o Scratch para criações de jogos, histórias e desenhos animados.

Para apresentar outras possibilidades da utilização do Scratch para criação de projetos, os alunos aprenderam a utilizar a webcam do notebook para capturar movimentos e, assim, criar outros tipos de projetos e até mesmo deixar os projetos feitos anteriormente mais interessantes. Nesse momento, eles tiveram a possibilidade de idealizar e criar os seus próprios projetos sem um tema predefinido. Os participantes demonstraram muita satisfação em realizar todo o processo de criação de projeto e com isso tivemos como resultado projetos diversificados e criativos. Um aspecto observado nessa aula foi que a utilização da webcam possibilitou a melhor compreensão de conceitos que eles tiveram dificuldades anteriormente, como o uso de operadores relacionais.

Outro conceito utilizado nessa unidade para incrementar os conhecimentos adquiridos foi o de clonagem. Na atividade proposta, os estudantes tiveram dificuldades em desassociar o clone de seu ator originário e para que eles pudessem ter uma melhor compreensão foi efetuada uma atividade desplugada demonstrando o conceito de clone. Após essa atividade, os participantes conseguiram compreender melhor o conceito apresentado.

Por fim, os estudantes montaram processos semelhantes aos que foram seguidos ao longo das atividades por meio da criação de uma tarefa e criação de um código com erros para execução do processo de debugue. Na primeira atividade, os estudantes criaram suas próprias atividades para que outras pessoas pudessem executá-las. Nesse ponto, observamos que não houve grande animação por parte dos participantes em apenas detalhar como fazer uma atividade. Na última tarefa, eles criaram um projeto e inseriram erros para que outras pessoas pudessem identifica-los. Nessa atividade, observamos grande interesse tanto na criação de projeto sem predeterminações como na inserção de erros.

\subsection{Hackathon}

Como forma de finalizar o curso, foi efetuada uma atividade de desenvolvimento livre. Nessa atividade, os estudantes poderiam utilizar qualquer conceito aprendido para criação 
Tabela 1. Resumo de aspectos positivos e negativos para cada unidade

\begin{tabular}{|c|c|c|c|}
\hline Unidade & Atividade & Observações positivas & Observações negativas \\
\hline \multirow{3}{*}{0} & $\begin{array}{l}\text { Apresentação Scratch e familiari- } \\
\text { dade com computador }\end{array}$ & & $\begin{array}{l}\text { Dificuldade com uso do touchpach } \\
\text { do notebook }\end{array}$ \\
\hline & Cadastro no site Scratch & & Dificuldade de leitura e escrita \\
\hline & Exploração do ambiente Scratch & $\begin{array}{l}\text { Interesse no uso da ferramenta e } \\
\text { apresentação de ideias; prazer em } \\
\text { apresentar seus feitos }\end{array}$ & $\begin{array}{l}\text { Queixas para escrever reflexões nos } \\
\text { diários }\end{array}$ \\
\hline \multirow[b]{3}{*}{1} & Conceitos de sequência e repetição & Atividade realizada à contento & \\
\hline & Criação de projeto com 10 blocos & $\begin{array}{l}\text { Turmas com alunos de escolas par- } \\
\text { ticulares e públicas com melhor } \\
\text { colaboração }\end{array}$ & $\begin{array}{l}\text { Dificuldade com as sequencias } \\
\text { lógicas e uso de repetições; ne- } \\
\text { cessária intervenção do professor }\end{array}$ \\
\hline & $\begin{array}{l}\text { Exploração de outros projetos do } \\
\text { ambiente Scratch }\end{array}$ & $\begin{array}{l}\text { Escolhas baseadas em gostos pesso- } \\
\text { ais (e não pela dificuldade técnica); } \\
\text { Atividade debatida entre pares }\end{array}$ & \\
\hline \multirow{5}{*}{2} & Colagem interativa sobre si mesmo & & $\begin{array}{l}\text { Não consideravam sua vida pessoal } \\
\text { interessante }\end{array}$ \\
\hline & Criar um grupo musical & $\begin{array}{l}\text { Prazer em criar e modificar projeto; } \\
\text { interesse na incorporação do áudio }\end{array}$ & \\
\hline & Quadrado laranja, círculo roxo & $\begin{array}{l}\text { Bastante empenho e dedicação; cri- } \\
\text { atividade em destaque }\end{array}$ & \\
\hline & Criação de personagem animado & Conexão com seu dia a dia & \\
\hline & Criar projeto próprio & Projetos diversificados & \\
\hline \multirow{6}{*}{3} & Criar um bloco para pular & & $\begin{array}{l}\text { Grande dificuldade com plano carte- } \\
\text { siano (intervenção do professor) }\end{array}$ \\
\hline & Personagens conversando & & Dificuldade com sincronização \\
\hline & Mudança de cenários Scratch & & $\begin{array}{l}\text { Dificuldade com o conceito de } \\
\text { proporção }\end{array}$ \\
\hline & Depuração de código & Realizada sem dificuldades & \\
\hline & Criar desenho colaborativo & Atividade considerada divertida & \\
\hline & Narração colaborativa de histórias & & $\begin{array}{l}\text { Incômodo ao alterar projeto de um } \\
\text { colega }\end{array}$ \\
\hline \multirow{4}{*}{4} & Reflexão sobre jogos & $\begin{array}{l}\text { Interesses similares entre meninos e } \\
\text { meninas }\end{array}$ & \\
\hline & Criação de um jogo & & $\begin{array}{l}\text { Dificuldade com conceitos de } \\
\text { variáveis e operadores relacionais }\end{array}$ \\
\hline & Controlar objeto em um jogo & & $\begin{array}{lll}\begin{array}{l}\text { Dificuldade } \\
\text { pontuação }\end{array} & \text { em } & \text { contabilizar } \\
\end{array}$ \\
\hline & Incrementar um jogo & $\begin{array}{l}\text { Projetos realizados de forma inde- } \\
\text { pendente }\end{array}$ & \\
\hline 5 & $\begin{array}{l}\text { Reflexão sobre que foi aprendido } \\
\text { Capturar movimentos com WebCam } \\
\text { Depuração }\end{array}$ & $\begin{array}{l}\text { Interesse em continuar o aprendi- } \\
\text { zado } \\
\text { Bastante interesse; melhor compre- } \\
\text { ensão de conceitos prévios } \\
\text { Grande interesse na criação de pro- } \\
\text { jetos próprios }\end{array}$ & $\begin{array}{l}\text { Pouco interesse na depuração de } \\
\text { projetos predefinidos }\end{array}$ \\
\hline 6 & Hackathon & $\begin{array}{l}\text { Bastante empenho e interesse na } \\
\text { colaboração }\end{array}$ & \\
\hline
\end{tabular}

de seu projeto. Além disso, os estudantes apresentaram seus projetos em um evento e os melhores projetos foram premiados. O projeto foi desenvolvido por grupos de até 5 pessoas (houve participantes que optaram por realizá-lo individualmente). Os alunos fizeram todo o processo de planejamento, divisão de tarefas e execução do projeto ao longo das aulas. Observamos que o trabalho colaborativo foi desenvolvido sem grandes problemas com grande empenho e interesse. Como resultado, tivemos projetos de diferentes níveis como, por exemplo, diversos tipo de jogos possuindo até 3 fases e histórias animadas.

A apresentação dos projetos fez parte de um marco final do curso e contou com a participação dos pais e de integrantes da secretaria de educação. Com a apresentação dos projetos percebemos a dificuldade dos alunos em fazer apresentações para um público maior, demonstrando dificuldade na exposição das ideias que pode ser explicada pela falta de exposição com esse tipo de apresentação. 
A tabela 1 sumariza os aspectos positivos e negativos apresentados nesta seção.

\section{Discussão}

Inicialmente identificamos dificuldades de leitura, escrita, interpretação de objetivos, exposição de ideias e falta de habilidade com o uso dos notebooks. Muitas dessas dificuldades foram superadas ao longo do curso.

O curso apresenta uma proposta pedagógica diferente da conhecida pelos estudantes, pois cabe ao aprendiz dar significado à atividade, incluindo novas formas de pensar e exercitar a criatividade. Isso requer maior compreensão do objetivo a ser atingido. Observamos que as atividades iniciais de cada unidade, que eram mais demonstrativas, eram realizadas com mais facilidade. Para atividades que necessitavam de maior senso crítico e criatividade, exemplificações desplugadas mostraram-se uteis para os estudantes.

Percebemos que o ambiente lúdico e criativo é muito importante no estimulo à colaboração. Muitas vezes, ao concluir uma atividade, os participantes auxiliavam outros por iniciativa própria. Percebemos também dificuldade em lidar com projetos de outras pessoas e que esta dificuldade pode ser sanada por meio de incentivo. Além disso, foi possível notar que os participantes possuíam mais facilidade em criar projetos totalmente idealizados por eles do que criar projetos com base em regras e temas predefinidos.

Por fim, vale ressaltar que após o contato inicial com o pensamento computacional, os alunos mostraram desenvoltura na missão de criar um projeto totalmente seu e apresentar para os colegas e para outras pessoas, demonstrando assim domínio e destreza nessa missão. Além disso, a grande procura por parte dos pais e dos alunos em outros cursos desse tipo que possam dar continuidade ao que foi aprendido demonstra que a ação foi considerada positiva por parte do público-alvo.

\section{Conclusões}

O ensino computacional vem sendo difundido mundialmente, desde as mais tenras idades. No Brasil, ainda existem diversos desafios a serem superados para sua inclusão no currículo do ensino básico. Entretanto, iniciativas locais por parte de pesquisadores possibilitam que os alunos desta modalidade tenham contato com a área e se beneficiem disso.

Neste artigo, relatamos o ensino computacional por meio de um curso de computação criativa realizado em 2018 e 2019, em uma cidade do sertão baiano. Como aspectos positivos destacamos o desenvolvimento de habilidades como a criatividade, colaboração, pensamento crítico, além do desenvolvimento pessoal dos alunos e o aumento do interesse em relação aos aspectos computacionais. Por meio desta iniciativa, entendemos que os desafios para a implantação de um curso desta natureza são facilmente superados desde que haja o apoio necessário. Graças aos resultados e a grande procura por parte do público-alvo, pretendemos levar o projeto para outras cidades, avaliar os efeitos a longo prazo e ampliar o público-alvo por meio da utilização de materiais apropriados para diferentes séries escolares que possibilitem o ensino gradual da computação.

\section{Referências}

[Bocconi et al. 2016] Bocconi, S., Chioccariello, A., Dettori, G., Ferrari, A., and Engelhardt, K. (2016). Developing computational thinking in compulsory education. Jrc science for policy report, European Commission, Joint Research Centre. 
[CSTA and ACM 2016] CSTA and ACM (2016). CSTA K-12 Computer Science Standards. The National Academies Press, Washington, DC.

[Cutumisu et al. 2019] Cutumisu, M., Adams, C., and Lu, C. (2019). A scoping review of empirical research on recent computational thinking assessments. Journal of Science Education and Technology, 28(6):651-676.

[Gal-Ezer and Stephenson 2014] Gal-Ezer, J. and Stephenson, C. (2014). A Tale of Two Countries: Successes and Challenges in K-12 Computer Science Education in Israel and the United States. ACM Trans. Comput. Educ., 14(2):8:1-8:18.

[Heintz et al. 2016] Heintz, F., Mannila, L., and Färnqvist, T. (2016). A review of models for introducing computational thinking, computer science and computing in k-12 education. In 2016 IEEE Frontiers in Education Conference (FIE), pages 1-9.

[IBGE 2020] IBGE (2020). Portal cidades. <https: //cidades.ibge.gov.br/>. [Online; accessed 12-June-2020].

[Lima et al. 2019] Lima, P., Vieira, P., and Brandão, L. (2019). Ensino de algoritmos, programação e matemática: panorama e estudo de caso para estudantes de escolas públicas brasileiras. In Anais do WIE, volume 25, page 697.

[Mohaghegh and McCauley 2016] Mohaghegh, D. M. and McCauley, M. (2016). Computational thinking: The skill set of the 21st century. IJCSIT, 7(3):1524-1530.

[Santos et al. 2019] Santos, J. A., Bittencourt, R., Dias, A. M., and de Santana, B. S. (2019). Pensamento computacional para alunos do ensino fundamental de escolas públicas em uma cidade de pequeno porte-um relato e análise de experiência. In Anais do WIE, volume 25, page 296 .

[Santos et al. 2018] Santos, P. S. C., Araujo, L. G. J., and Bittencourt, R. A. (2018). A Mapping Study of Computational Thinking and Programming in Brazilian K-12 Education. In FIE 2018 - IEEE Frontiers in Education Conference, pages 1-8. IEEE.

[SBC 2018] SBC (2018). Nota Técnica da Sociedade Brasileira de Computação sobre a BNCC-EF e a BNCC-EM. [Online; accessed 05-June-2020].

[Torres et al. 2018] Torres, F., Junior, M., Dantas, R., Mascena, L., and Damasceno, A. (2018). Ensinando o pensamento computacional usando linguagens de programação no alto sertão da paraíba. In Anais do WIE, volume 24, page 660.

[Voogt et al. 2013] Voogt, J., Erstad, O., Dede, C., and Mishra, P. (2013). Challenges to learning and schooling in the digital networked world of the 21 st century. Journal of computer assisted learning, 29(5):403-413.

[Wing 2006] Wing, J. M. (2006). Computational Thinking. Communications of the ACM, 49(3):33-35. 